American Journal of Pharmaceutical Education 2019; 83 (8) Article 7037.

\title{
RESEARCH
}

\section{An Elective Course for Student Pharmacists on Pharmaceutical Industry Practice}

\author{
Bobby Jacob, PharmD, Samuel K. Peasah, PhD \\ Mercer University College of Pharmacy, Atlanta, Georgia \\ Submitted February 26, 2018; accepted August 22, 2018; published October 2019.
}

Objective. To design and implement an elective course on pharmaceutical industry practice and assess its impact on student pharmacists' knowledge and perceptions.

Methods. This was a two-credit hour, elective course offered to second- and third-year student pharmacists during the 2015 and 2016 spring semesters. The goal of this course was to provide instruction regarding skills and competencies for pharmaceutical industry practice. Curricular content included didactic instruction, assigned readings, weekly quizzes, classroom discussion of industry-based functions and responsibilities, and three application projects. A 65 -item survey instrument was developed to assess changes in student pharmacists' perceptions and understanding of pharmaceutical industry practice.

Results. Forty-four students enrolled in the elective course over the two offerings. The average rating on the course evaluation was 4.7 out of 5 . Average scores on graded quizzes were $90 \%$, and grades on the application projects ranged from $92 \%$ to $99 \%$. There was an increase in the number of students who perceived that they understood various functions and roles in the pharmaceutical industry, and who rated themselves confident in completing unique tasks associated with pharmaceutical industry practice. Furthermore, there was an increase in the number of students who reported improved perceptions regarding the trustworthiness of the pharmaceutical industry, costs of prescription medications, and promotional advertising for branded prescription medication.

Conclusion. Student pharmacists' perceptions of the course were positive, and overall perceptions and understanding of the pharmaceutical industry improved. Active collaboration between colleges and pharmaceutical companies can lead to positive educational opportunities for students interested in pharmaceutical industry careers.

Keywords: pharmaceutical industry, perception, student pharmacist

\section{INTRODUCTION}

The pharmaceutical industry positively contributes to patient welfare by developing prescription medications that are used to treat a myriad of disease states and medical conditions. Pharmacists are employed extensively throughout the pharmaceutical industry with diverse functions and responsibilities that include roles in medical affairs, regulatory affairs, drug development, outcomes research, pharmacovigilance, and commercial marketing. Required components of the pharmacy curriculum provide training in skills related to clinical knowledge, literature evaluation, leadership, and communication, which can position student pharmacists well to pursue postgraduate training and career

Corresponding Author: Bobby Jacob, Mercer University College of Pharmacy, 3001 Mercer University Dr., Atlanta, GA 30341. Tel: 678-547-6307. Fax: 678-547-6384. E-mail: Jacob_bc@mercer.edu opportunities in the pharmaceutical industry. ${ }^{1}$ There are relatively limited curricular content devoted to the many pharmacist roles that are unique to the pharmaceutical industry setting. Elective courses can provide exposure to these functions and may assist student pharmacists who desire to positively differentiate themselves in a competitive job market. ${ }^{2}$

Several studies have evaluated medical students' perceptions of the pharmaceutical industry; however, pharmacy pedagogical literature on the pharmaceutical industry is limited. ${ }^{3-7}$ Hartman and colleagues described the design and implementation of two separate pharmaceutical industry elective courses and assessed the impact of these courses on student pharmacists' selection of advanced pharmacy practice experiences (APPEs) and pursuit of pharmaceutical industry fellowships. ${ }^{8}$ This study found that $31 \%$ of students who took a pharmaceutical industry-based APPE had previously taken one of the 


\section{American Journal of Pharmaceutical Education 2019; 83 (8) Article 7037.}

elective courses; $18 \%$ of graduating students who took one of the elective courses pursued a postgraduate pharmaceutical industry-based fellowship program compared to only $5 \%$ of graduating students who had not taken these elective courses. Mihm described the design of an elective course that placed student pharmacists in marketing teams overseeing a hypothetical new product launch. ${ }^{9}$ Groups were tasked with preparing an abbreviated marketing plan and developing a Food and Drug Administration (FDA) compliant direct-to-consumer (DTC) advertisement. Neither of these studies evaluated students' perceptions of the pharmaceutical industry or their perceived confidence to perform tasks associated with industry practice.

The objective of this study was to describe the design and implementation of an elective course for student pharmacists on a broad range of roles and functions unique to pharmaceutical industry practice. Furthermore, the study evaluated changes in student pharmacists' perceptions regarding the pharmaceutical industry, familiarity with roles and responsibilities of pharmacists within the pharmaceutical industry, and confidence in performing specific tasks associated with pharmaceutical industry practice.

\section{METHODS}

This course was a two-credit hour, weekly elective offered during the 2015 and 2016 spring semesters to second- and third-year student pharmacists. All students had previously participated in a dedicated class session on the pharmaceutical industry during a required first-year introductory course which included discussions related to the prescription drug development process and career opportunities in the pharmaceutical industry. The elective course was developed and coordinated by a faculty member who had prior work experience in the medical affairs organization of a US-based pharmaceutical company. Electronic and live announcements regarding the course were made to all second- and third-year students and those with an explicit interest in pursuing careers in the pharmaceutical industry were strongly encouraged to enroll in the course.

The course was designed to introduce student pharmacists to foundational knowledge, skills, and competencies required for selected entry-level and advanced practice roles in the pharmaceutical industry. The course topics and learning objectives are shown in Appendix 1 and Appendix 2. The course coordinator was present for all class sessions to take roll, administer quizzes, and introduce guest speakers. Attendance was required for all the sessions to facilitate didactic instruction and interaction with the pharmaceutical industry-based speakers. Speakers were identified by the course coordinator from pharmaceutical companies around the United States and served as content experts on various course topics. Four- teen external pharmaceutical industry-based speakers from nine separate companies comprised the course faculty. Over a period of 12 months the course coordinator developed the course structure and identified appropriate topics and speakers. In addition, the course coordinator provided four hours of didactic instruction and classroom facilitation. Guest faculty members reported allocating two to 10 hours for initial lecture preparation depending on the course topic and one to three hours in updating the lecture content for the subsequent year. In addition, faculty members provided their time for the two-hour class sessions as well as for any travel to campus, which often included arrangements for out of state travel. Didactic lectures were delivered primarily using PowerPoint presentations, which were made available to the students on the day prior to class.

The elective course was divided into three focus areas: medical affairs, drug development, and interfacing with internal and external customers. Course work consisted of didactic lectures, assigned readings, weekly quizzes, and application projects. Classroom sessions were constructed with an expectation that students would increase foundational knowledge by actively engaging in discussions facilitated by pharmaceutical industry-based speakers. Most class sessions began with the course coordinator administering a short quiz (one to five questions), which evaluated students' understanding of either the previous week's content or assigned pre-class readings. Assigned pre-class readings, obtained from the primary literature or FDA guidance documents, were related to the topic for classroom discussion. In addition, students used lecture notes and assigned readings to complete application projects. The projects provided students with the opportunity to apply concepts related to specific functions that are common entry-level roles for pharmacists in the pharmaceutical industry. Application projects were evaluated by the course coordinator and included two individual projects and one group presentation. Students' grading assessment consisted of weekly quizzes (20\%) and application projects including the promotional advertisement review exercise (20\%), medical information response letter $(20 \%)$, and group managed care presentation (40\%).

The promotional advertisement review exercise required students to evaluate the appropriateness of an assigned DTC television advertisement for a branded prescription product (Table 1). Televised advertisements were identified by the course coordinator from YouTube and assigned to individual students via email. Second-year student pharmacists received advertisements pertaining to products in psychiatry, neurology, or cardiovascular disease as these were the only therapeutic topics to be completed during the second professional year of the required 


\section{American Journal of Pharmaceutical Education 2019; 83 (8) Article 7037.}

Table 1. Grading Rubric for Individual Application Projects Completed by Student Pharmacists Enrolled in an Elective Course on Pharmaceutical Industry Practice

\begin{tabular}{|c|c|c|}
\hline Category & Description & Points \\
\hline \multicolumn{3}{|c|}{ Promotional Advertisement Review Exercise ${ }^{\mathrm{a}}$} \\
\hline FDA indication & $\begin{array}{l}\text { List the specific FDA indication that is being marketed by the assigned } \\
\text { DTC advertisement. }\end{array}$ & 10 \\
\hline Pivotal clinical trial(s) & $\begin{array}{l}\text { Provide a brief summary of the pivotal trial(s) that is being used to } \\
\text { support the FDA indication that is being marketed by the assigned } \\
\text { DTC advertisement. }\end{array}$ & 20 \\
\hline Overall evaluation & $\begin{array}{l}\text { Address whether you consider the advertisement as a whole is fair and } \\
\text { balanced. }\end{array}$ & 20 \\
\hline Regulatory violations & $\begin{array}{l}\text { Address if there are any regulatory violations in the advertisement } \\
\text { including omission of risk information, unsubstantiated claims, } \\
\text { promotion of unapproved uses, or overstatement of efficacy. }\end{array}$ & 10 \\
\hline Cover letter & $\begin{array}{l}\text { Address the response to a physician and re-state the question that was } \\
\text { asked. } \\
\text { In addition, include any relevant disclaimer statements regarding the } \\
\text { response. }\end{array}$ & 10 \\
\hline Summary page & $\begin{array}{l}\text { Provide a one-page summary of the response in bullet points that } \\
\text { addresses efficacy and safety information related to the question from } \\
\text { the product's package insert and relevant published trials }\end{array}$ & 20 \\
\hline Body & $\begin{array}{l}\text { The body should include a more detailed, scientifically written overview } \\
\text { of all relevant efficacy and safety information regarding the question } \\
\text { that includes data from the product's package insert and published } \\
\text { primary literature. }\end{array}$ & 60 \\
\hline
\end{tabular}

Abbreviations: DTC = direct to consumer, FDA=Food and Drug Administration

${ }^{\text {a }}$ Students were assigned a direct-to-consumer television advertisement for a branded prescription medication and were required to individually submit a written evaluation using concepts covered during class. The course coordinator evaluated all submissions and assigned a grade out of 100 points based on the grading rubric. The grade for this assignment comprised $20 \%$ of the total course grade

${ }^{\mathrm{b}}$ Students were assigned a drug information question for a branded prescription medication and were required to individually develop and submit a written medical information response letter using the concepts on pharmaceutical industry-based drug information covered during class. The course coordinator evaluated all submissions and assigned a grade out of 100 points based on a grading rubric. The grade for this assignment comprised $20 \%$ of the total course grade

curriculum at the study institution. Third-year student pharmacists could be assigned televised advertisements for branded products in a broader range of therapeutic areas. Prior to the class session on Principles of Promotional Review, students were asked to view their assigned DTC televised advertisement and read the branded product's package insert. Furthermore, prior to class, students were required to read the FDA guidance document, "Presentation of Risk Information in Prescription Drug and Medical Device Promotion."10 During class, students reviewed various concepts related to the medical review of promotional advertising, including the importance of fair balance, on-label versus off-label information, false and misleading claims, unsubstantiated claims, and omission of risk information. In addition, the course coordinator oriented the students to the Office of Prescription Drug Promotion (OPDP) within the FDA and the corresponding website for warning letters to pharmaceutical companies. Students reviewed warning letters from the previous calendar year and discussed their findings with fellow students before completing the individual application project on their own. 


\section{American Journal of Pharmaceutical Education 2019; 83 (8) Article 7037.}

The second individual application project required students to develop a written medical information response letter for an assigned drug information question on a branded prescription product (Table 1). The students had to write the letter from the perspective of the pharmaceutical industry and the content had to be in compliance with regulatory guidelines. Prior to the class session on Medical Communications, students were required to read the Drug Information Association (DIA) Core Curriculum on Medical Communications, which provides an overview of best practices related to the provision of written drug information responses by individuals in the pharmaceutical industry. ${ }^{11}$ The course coordinator developed a specific drug information question related to a branded prescription drug that students would also be learning about in their separate required therapeutic modules: a cardiovascular module for second-year students and an infectious disease module for third-year students. During the class session on Medical Communications, the course coordinator reviewed principles of good pharmaceutical industry-based drug information practice, including understanding solicited versus unsolicited requests for information, scientific balance, strength and quality of evidence, and use of disclaimers. Students were asked to address their medical information response letter as if the question came from a practicing physician. The medical information response letter had to be five to six pages in length, appropriately incorporate principles of industrybased drug information practice discussed in class, and non-promotional in nature. Students using any form of plagiarism received zero points for the assignment and were subject to disciplinary action.

Finally, students were required to work in groups to complete a managed care presentation that served as a capstone project, incorporating learnings from class sessions on medical communications, drug development, clinical development, pharmacovigilance, health economics and outcomes research, and market access (Table 2). This application project was also designed to provide students with an opportunity to appreciate the role of field-based medical affairs personnel in dealing with external customers like pharmacy and therapeutics committees. Secondyear student pharmacist groups were assigned the specific anticoagulant or antiplatelet agent that was the focus of their medical information response letter. Thirdyear student pharmacist groups were assigned a specific antibiotic. Along with their presentation slides, students were required to submit an evidence table that included information on study design, patient population, interventional arms, efficacy, and safety results from pivotal clinical trials for their assigned product. Students groups were also encouraged to consult with the Academy of Managed Care Pharmacy (AMCP) Format on Formulary Submissions for additional guidance on the presentation. ${ }^{12}$

Table 2. Grading Rubric for Group Managed Care Presentations by Student Pharmacists Enrolled in an Elective Course on Pharmaceutical Industry Practice ${ }^{\mathrm{a}}$

\begin{tabular}{lc}
\hline Category & Description \\
\hline Disease state overview & Using an appropriate published clinical practice guideline, provide a brief \\
summary of the disease state(s) where the product is FDA indicated. & Highlight relevant information from the product package insert including \\
Product information & indications, contraindications, warnings, precautions, dosing, \\
& administration, and any other items that are deemed pertinent for \\
& consideration of the branded product. \\
Sumporting clinical & were used to support the FDA indications. Optionally, students may \\
evidence & include information on off-label clinical studies that groups feel would \\
& be important for consideration. \\
Provide a summary of any health economic studies that are directly \\
relevant to the product. If this information is not available, groups may \\
include health economic studies related to the disease state(s) in \\
question.
\end{tabular}

Abbreviations: FDA=Food and Drug Administration

${ }^{a}$ Students were placed into groups that were assigned a branded prescription medication. For a capstone project, student groups were required to develop a presentation for a mock Pharmacy and Therapeutics Committee using concepts covered throughout the course.The course coordinator evaluated all submissions and assigned a grade out of 100 points based on the grading rubric. The grade for this assignment comprised $40 \%$ of the total course grade 


\section{American Journal of Pharmaceutical Education 2019; 83 (8) Article 7037.}

Course evaluations were administered at the end of each semester and included a five-item Likert scale $(5=$ excellent, $4=$ more than adequate, $3=$ adequate, $2=$ less than adequate, and $1=$ poor). Specific areas for students to evaluate included organization of the course, coordination of team teaching, value of required materials in promoting learning, effectiveness of technology use in the course, value of active-learning activities in promoting learning, and appropriateness of evaluation methods in reflecting course content. The course also incorporated a survey evaluation of changes in student pharmacists' perceptions of the pharmaceutical industry, familiarity with various roles and responsibilities for pharmacists in the pharmaceutical industry, and confidence in performing selected pharmaceutical industry-based tasks. The original concept for this evaluation came in part from a publicly available survey developed by the Kaiser Family Foundation and Harvard University School of Public Health that assessed the general public's perceptions regarding prescription drugs and the pharmaceutical industry. ${ }^{13}$ Several questions from the survey were modified and additional questions were developed to form a new 65 -item survey instrument which was in a 5-point, Likert-scale format with responses ranging from strongly agree to strongly disagree. The modified survey instrument was tested with first-year student pharmacists at the study institution, and feedback was incorporated into the version used in the elective course. Positively and negatively worded statements were included in the survey to minimize the risk for acquiescent response bias (tendency to agree with statements regardless of the content). Questions were categorized as those pertaining to student pharmacists' perceptions of the favorability and trustworthiness of the pharmaceutical industry, safety and costs associated with prescription drugs, promotional advertising for prescription drugs, and governmental regulation of the drug development process. Furthermore, questions were included related to students' perceived familiarity with different types of drug information communicated from the pharmaceutical industry, familiarity with roles and responsibilities for pharmacists within the pharmaceutical industry, and self-reported confidence in delivering specific types of drug information from the perspective of the pharmaceutical industry. The survey also included questions on demographics, work history, and future career plans related to the pharmaceutical industry.

The survey was offered to students enrolled in the pharmaceutical industry elective at the beginning (precourse survey) and end of the spring semesters (post-course survey) in 2015 and 2016. The survey was prepared using Qualtrics (Qualtrics Lab, Provo, UT), a data collection and analysis software program. Students received an electronic link to the survey and were given 30 minutes on the first and last day of class to complete the survey. Participation in the study was voluntary, and informed consent was obtained from all participants. Institutional review board approval was obtained from the study institution. Demographics of the student respondents were summarized. For ease of presentation and interpretation, the 5-point Likert scale was collapsed into a 2-point Likert scale on which agree or strongly agree responses were grouped together (agreed with the statement) and the rest of the responses were classified as disagreed with the statement. Results are presented as the percentage of students who agreed or strongly agreed with various statements related to the pharmaceutical industry during the pre-course survey and the post-course survey. Differences between the pre-course survey and post-course survey responses were analyzed using the signed ranked test. SAS, version 9.3 (SAS Institute Inc, Cary, NC) was used for statistical analyses.

\section{RESULTS}

Forty-four student pharmacists enrolled in the elective course during the 2015 and 2016 spring semesters. Nineteen students completed the course evaluations ( $43 \%$ response rate), and the average rating on all items was 4.7 out of 5.0. Students' impressions were positive regarding organization of the course (4.7), value of required material in promoting learning (4.7), value of active-learning activities in promoting learning (4.7), and appropriateness of evaluation methods (4.9). The average grade for quiz assessments was $90 \%$. Average grades for the application projects were as follows: promotional review exercise (92\%), medical information response letter (98\%), and group managed care presentation (99\%). Eleven students $(25 \%)$ who enrolled in the course were able to complete a pharmaceutical industry-based APPE during the fourth year of the professional program.

Forty-two student pharmacists completed the precourse survey and 44 student pharmacists completed the post-course survey. Forty-one student pharmacists completed both surveys (93\% response rate). Participating students were mostly in the second-year of the program $(84 \%)$ and only three students (7\%) had prior work experience in the pharmaceutical industry. Students reported a favorable view of the pharmaceutical industry throughout the course ( $88 \%$ of students on the pre-course survey and $90 \%$ of students on the post-course survey). By the end of the course, greater than $95 \%$ of student pharmacists believed that the pharmaceutical industry offered pharmacists the opportunity to make valuable contributions to patient care (98\%), apply skills and competencies learned during pharmacy school (98\%), and pursue various career pathways (98\%). Approximately $75 \%$ of students 


\section{American Journal of Pharmaceutical Education 2019; 83 (8) Article 7037.}

reported that they planned on pursuing a career in the pharmaceutical industry at some point after graduation.

During the course, there was an increase in the number of students who felt confident in their understanding of the pharmaceutical industry $(18 \%$ to $98 \%, p<.001)$. Specifically, there was an increase in the number of students who reported being confident in their ability to write a medical information response letter from a pharmaceutical industry perspective ( $8 \%$ to $85 \%, p<.001)$, discuss differences in drug information practice in the pharmaceutical industry compared to other pharmacy practice settings (23\% to $95 \%$, $p<.001$ ), provide medical review for a promotional advertisement $(10 \%$ to $83 \%, p<.001)$, and develop a managed care presentation based on criteria in the AMCP Formulary Dossier Format (20\% to $60 \%, p<.001)$. Furthermore, there were increased numbers of students who reported improved understanding of roles in regulatory affairs, legal affairs, publications, clinical study monitoring, pharmacovigilance, health economics and outcomes research, market access, and commercial marketing.

Student pharmacists' perceptions of the pharmaceutical industry appear to have improved in general during the course and are noted in Table 3. There was an increase in the number of students who believed the pharmaceutical industry makes a comparatively greater contribution to society's welfare than other industries ( $54 \%$ to $80 \%, p=.007$ ). Furthermore, there was an increase in the number of students who believed the pharmaceutical industry was reliable in providing drug information about product efficacy (39\% to $78 \%, p<.001)$ and adverse events and safety concerns $(41 \%$ to $78 \%, p<.001)$, and in informing the public quickly of newly discovered safety concerns $(51 \%$ to $73 \%, p=.02)$. There were increases in the number of student pharmacists who believed that the benefits of prescription drugs justify the price society must pay for them ( $32 \%$ to $56 \%, p=.03)$ and that prescription drugs reduce long-term, overall health care costs ( $73 \%$ to $93 \%, p=.04)$. However, by the end of the semester, only $46 \%$ of students felt that prescription drug costs in the United States were reasonable.

As shown in Table 4, the number of students who considered DTC advertising to be good for patients and society doubled ( $22 \%$ to $44 \%, p=.02)$, and those who believed that additional government regulation was needed to ensure that advertising was truthful and accurate declined (46\% to $22 \%$, $p=.04)$. Despite this, there was not much change in the percentage of student pharmacists who believed that pharmaceutical companies should not be allowed to market their products directly to consumers (34\% to $37 \%$ ).

\section{DISCUSSION}

The elective course for student pharmacists described here covers a broad range of pharmacist roles that are unique to pharmaceutical industry practice. This study adds to the pedagogical literature on elective courses by being the first to evaluate changes in student pharmacists' perceptions regarding the pharmaceutical industry, familiarity with roles and responsibilities of pharmacists within the pharmaceutical industry, and self-perceived confidence in performing specific tasks uniquely associated with pharmaceutical industry practice. Student response to the course was positive. There were increases in the number of students who reported improved familiarity with a diverse range of functions in the pharmaceutical industry and improved confidence in performing specific tasks uniquely associated with pharmaceutical industry practice. In addition, positive changes were noted in student pharmacists' perceptions regarding the trustworthiness of the pharmaceutical industry, prescription drug costs, and promotional advertising.

Pedagogical studies related to pharmacy education and the pharmaceutical industry are limited and have focused mainly on student pharmacists' perceptions of pharmaceutical industry-based promotional marketing practices. ${ }^{14,15}$ Prior studies on elective courses for student pharmacists have focused on promotional activities and medical communications. ${ }^{8,9}$ Pharmacists have the opportunity to pursue a broad range of functions that extend beyond these traditional roles within the pharmaceutical industry. This course expands on previous pedagogical studies by including discussions regarding the legal and regulatory oversight of the pharmaceutical industry, phase 3 and 4 clinical development, pharmacovigilance, health economics, outcomes research, market access, publication strategy, and business leadership. Furthermore, unlike previous studies, this course incorporated three application projects that were designed to simulate scenarios where students had to apply concepts from the perspective of a pharmacist performing common entrylevel functions. The course coordinator relied on previous work experience and contacts within the pharmaceutical industry to identify a broad range of topics that would provide students with a holistic view of pharmacist roles within pharmaceutical industry practice. One important approach in achieving this objective was to identify and incorporate speakers who currently worked in the pharmaceutical industry so that students would receive information on current standards of practice. The course coordinator spoke with each speaker prior to the start of the course to discuss the overall goals of the course. It was important to allow speakers to have the flexibility to create individual didactic content, associated learning objectives, and active-learning classroom exercises based on their own experience and judgement. The course coordinator maintained contact with guest speakers in order to 


\section{American Journal of Pharmaceutical Education 2019; 83 (8) Article 7037.}

Table 3. Student Pharmacists' Perceptions of the Pharmaceutical Industry and Prescription Drugs Before and After Completing an Elective Course on Pharmaceutical Industry Practice $(\mathrm{N}=41)^{\mathrm{a}}$

\begin{tabular}{|c|c|c|c|}
\hline Statement & Pre-course, $(\%)$ & Post-course, $(\%)$ & $p$ Value $^{\mathrm{b}}$ \\
\hline I have a favorable view of the pharmaceutical industry & 88 & 90 & $>.99$ \\
\hline $\begin{array}{l}\text { Prescription drugs developed over the past } 20 \text { years have had a positive } \\
\text { effect on society in the United States }\end{array}$ & 93 & 98 & .63 \\
\hline The impact of prescription drugs on our society is negligible & 10 & 10 & $>.99$ \\
\hline $\begin{array}{l}\text { Pharmaceutical companies that research and develop new drugs make a } \\
\text { greater contribution to society's welfare compared to companies in other } \\
\text { industries }\end{array}$ & 54 & 80 & .007 \\
\hline $\begin{array}{l}\text { Pharmaceutical companies are an example of bad business and health care } \\
\text { practice in our society }\end{array}$ & 2 & 10 & .38 \\
\hline $\begin{array}{l}\text { Pharmaceutical companies are trustworthy in offering reliable information } \\
\text { about the efficacy of their products }\end{array}$ & 39 & 78 & $<.001$ \\
\hline $\begin{array}{l}\text { Pharmaceutical companies are trustworthy in offering reliable information } \\
\text { about safety concerns and adverse side effects related to their products }\end{array}$ & 41 & 78 & $<.001$ \\
\hline $\begin{array}{l}\text { Pharmaceutical companies are trustworthy to develop new and effective } \\
\text { prescription drugs }\end{array}$ & 76 & 90 & .11 \\
\hline Pharmaceutical companies are trustworthy to price their products fairly & 24 & 46 & .04 \\
\hline $\begin{array}{l}\text { Pharmaceutical companies are trustworthy to inform the public quickly } \\
\text { when they learn of a safety concern with one of their products }\end{array}$ & 51 & 73 & .02 \\
\hline I am confident that prescription drugs sold in the United States are safe & 71 & 88 & .07 \\
\hline $\begin{array}{l}\text { Pharmaceutical companies do not do enough to ensure the safety of } \\
\text { prescription drugs }\end{array}$ & 12 & 12 & $>.99$ \\
\hline $\begin{array}{l}\text { There should be more government regulation to ensure the safety of } \\
\text { prescription drugs }\end{array}$ & 24 & 15 & .39 \\
\hline The cost of prescription drugs in the United States is reasonable & 20 & 46 & .001 \\
\hline $\begin{array}{l}\text { Insurance companies should only pay for prescription drugs that have been } \\
\text { proven to be more effective or safer than existing available treatments }\end{array}$ & 41 & 49 & .61 \\
\hline $\begin{array}{l}\text { The government should only approve prescription drugs that have been } \\
\text { proven to be more effective or safer than existing available treatments }\end{array}$ & 49 & 39 & .39 \\
\hline $\begin{array}{l}\text { The benefits of prescription drugs justify the price society must pay for } \\
\text { them }\end{array}$ & 32 & 56 & .03 \\
\hline $\begin{array}{l}\text { Prescription drugs do not reduce the need for expensive medical procedures } \\
\text { and hospitalizations }\end{array}$ & 12 & 15 & $>.99$ \\
\hline In the long run, prescription drugs reduce health care costs & 73 & 93 & .04 \\
\hline $\begin{array}{l}\text { There should be more government regulation on pricing of prescription } \\
\text { drugs }\end{array}$ & 46 & 37 & .34 \\
\hline $\begin{array}{l}\text { Pharmaceutical companies do not do enough to help people who cannot } \\
\text { afford their medication }\end{array}$ & 24 & 20 & .73 \\
\hline
\end{tabular}

${ }^{a}$ Students were asked to read the statements and indicate their level of agreement or disagreement $(1=$ strongly agree, $2=$ agree, $3=$ neither agree or disagree, $4=$ disagree, $5=$ strongly disagree). For ease of presentation and interpretation, the 5-point Likert scale was collapsed into a 2-point Likert scale where agreed or strongly agreed responses were grouped together (agreed with the statement) and the rest were classified as did not agree with the statement. The table indicates the percentage of students who agreed or strongly agreed during the pre-course survey compared to the post-course survey

${ }^{\mathrm{b}}$ Statistical analysis was performed using the Signed Rank test to determine the significance, defined as $p<.05$, of differences between the precourse survey and post-course survey

ensure continuity from week to week and to avoid unnecessary overlap. In addition to didactic instruction, application projects were specifically designed to reinforce didactic concepts and to allow for practical application of concepts from a pharmaceutical industry perspective. These assignments centered on roles common for medical affairs personnel but required students to use understanding of critical literature evaluation, regulatory oversight, health economics, drug development, writing, and verbal communication. The layout of the course and associated application activities allows for implementation by a faculty member within other colleges and schools of pharmacy.

Another unique aspect of this study was the incorporation of a survey to evaluate changes in student 


\section{American Journal of Pharmaceutical Education 2019; 83 (8) Article 7037.}

Table 4. Student Pharmacists' Perceptions of Prescription Drug Direct to Consumer Advertising Before and After Completing an Elective Course on Pharmaceutical Industry Practice $(\mathrm{N}=41)^{\mathrm{a}}$

\begin{tabular}{|c|c|c|c|}
\hline Statement & Pre-Course, $\%$ & Post-Course, $\%$ & $p$ Value $^{\text {b }}$ \\
\hline $\begin{array}{l}\text { Direct to consumer advertising on the television and the Internet is good for } \\
\text { patients and society }\end{array}$ & 22 & 44 & .02 \\
\hline $\begin{array}{l}\text { There is not enough government regulation to ensure that prescription drug } \\
\text { advertising is truthful and accurate }\end{array}$ & 46 & 22 & .04 \\
\hline $\begin{array}{l}\text { Prescription drug advertising does a good job of describing potential } \\
\text { adverse side effects and safety considerations for products }\end{array}$ & 32 & 71 & $<.001$ \\
\hline $\begin{array}{l}\text { Prescription drug advertising does a good job of describing conditions or } \\
\text { disease states that prescription drugs are used to treat }\end{array}$ & 59 & 56 & $>.99$ \\
\hline Prescription drug advertising is usually inaccurate and misleading & 17 & 15 & $>.99$ \\
\hline $\begin{array}{l}\text { Prescription drug advertising educates people about valuable treatments } \\
\text { and encourages them to seek medical attention for conditions they might } \\
\text { not be aware of }\end{array}$ & 56 & 61 & .77 \\
\hline $\begin{array}{l}\text { Pharmaceutical companies spend too much money on prescription drug } \\
\text { advertising }\end{array}$ & 54 & 46 & .55 \\
\hline
\end{tabular}

${ }^{a}$ Students were asked to read the statements and indicate their level of agreement or disagreement $(1=$ strongly agree; $2=$ agree; $3=$ neither agree or disagree; $4=$ disagree; $5=$ strongly disagree). For ease of presentation and interpretation, the 5-point Likert scale was collapsed into a 2-point Likert scale where agreed or strongly agreed responses were grouped together (agreed with the statement) and the rest were classified as did not agree with the statement. The table indicates the percentage of students who agreed or strongly agreed during the pre-course survey compared to the post-course survey

${ }^{\mathrm{b}}$ Statistical analysis was performed using the Signed Rank test to determine the significance, defined as $p<.05$, of differences between the precourse survey and post-course survey

pharmacists' perceptions regarding the pharmaceutical industry, familiarity with roles and responsibilities of pharmacists within the pharmaceutical industry, and self-perceived confidence in performing specific tasks associated with practice in the pharmaceutical industry. Students' views of the pharmaceutical industry can be shaped by many factors and can often include misconceptions that arise out of lack of knowledge regarding pharmaceutical industry practices. Even though students came into the course with a positive view of the pharmaceutical industry, there was an increase in the number of students that perceived the pharmaceutical industry to make a comparatively greater contribution to society than other industries. In addition, there was an increase in the number of students that positively viewed the reliability of drug information from the pharmaceutical industry related to efficacy and safety of products. There were also increases in the number of students who had positive impressions of promotional advertising and cost implications associated with use of prescription drugs. The incorporation of active-learning exercises may provide some explanation for these observed changes. The course emphasized the need for students to understand usual practices within the industry and the federal regulations that governed these practices. Furthermore, the course incorporated several application projects that allowed students to experience the complexity of functions by requiring them to perform various tasks from the perspective of a pharmacist who would be working at a pharmaceutical company. Active-learning exercises may allow students to gain an appreciation for the specific processes associated with various tasks and the complexity of these functions.

Several challenges exist for colleges that seek to implement similar elective courses for their students. Primarily, faculty members with an interest in pharmaceutical industry practice must be identified. Furthermore, collaborative relationships must be developed with practitioners in the pharmaceutical industry who can represent a broad range of industry-based functions and responsibilities, and who have interest and skills for didactic instruction. Another challenge for the academy to consider is the need for developing experiential education opportunities that 


\section{American Journal of Pharmaceutical Education 2019; 83 (8) Article 7037.}

provide a good next step for students who have gained a foundation of knowledge through elective courses. In this study, $75 \%$ of the students who took the elective course reported wanting to pursue a career in the pharmaceutical industry; however, only one quarter of enrolled students took a pharmaceutical industry-based APPE. This relatively low percentage most likely reflects the limited number of experiential opportunities that the pharmaceutical industry makes available to students through colleges. This effect can be complicated in that geographic distribution of pharmaceutical companies is not uniform around the country. Hartman and colleagues similarly found a very low percentage of students that were able to pursue experiential opportunities in the pharmaceutical industry. ${ }^{8}$ The opportunity exists for productive collaboration between colleges and pharmaceutical companies to address this challenge and develop experiential and postgraduate opportunities that meet student interest and demand.

There are several limitations to this study including likely selection bias as students in this course represented those who were most motivated to learn about the pharmaceutical industry. Despite this, student responses reflected an improvement in confidence with a variety of pharmaceutical industry specific tasks. Another limitation is that student perceptions of the pharmaceutical industry would be expected to improve as they were mostly exposed to instructors who currently worked in the pharmaceutical industry. Furthermore, the survey used to evaluate students' perceptions did not include a validated knowledge assessment, which would have enhanced the ability to objectively measure changes in student learning. Future work should focus on the development of a validated knowledge assessment that can be used to properly evaluate changes in student knowledge regarding pharmaceutical industry practice.

\section{CONCLUSION}

This study demonstrates the feasibility of successfully implementing an elective course for student pharmacists that provides instruction and application opportunities regarding a broad range of pharmacist roles that are unique to the pharmaceutical industry setting. Collaboration between colleges of pharmacy and pharmaceutical manufacturers can lead to an increased number of curricular offerings. Furthermore, these courses can assist students as they seek to expand familiarity and knowledge regarding prescription drug development, commercialization, and the role of the pharmaceutical industry in modern health care delivery.

\section{REFERENCES}

1. American Council for Pharmacy Education (ACPE).

Accreditation standards and guidelines. https://www.acpeaccredit.org/pdf/S2007Guidelines2.0_ChangesIdentifiedInRed.pdf. Accessed July 14, 2018.

2. Medina MS, Plaza CM, Stowe CD, et al. Center for the Advancement of Pharmacy Education 2013 educational outcomes. Am J Pharm Educ. 2013;77(8):Article 162.

3. Yeh JS, Austad KE, Franklin JM, et al. Medical schools' industry interaction policies not associated with trainees' self-reported behavior as residents: results of a national survey. J Grad Med Educ. 2015;7:595-602.

4. Sierles FS, Kessler KH, Mintz M, et al. Changes in medical students' exposure to and attitudes about drug company interactions from 2003 to 2012: a multi-institutional follow-up survey. Acad Med. 2015;90:1137-1146.

5. Austad KE, Avorn J, Franklin JM, Campbell EG, Kesselheim AS. Association of marketing interactions with medical trainees'

knowledge about evidence-based prescribing: results from a national survey. JAMA Intern Med. 2014;174:1283-1290.

6. Austad KE, Avorn J, Franklin JM, Kowal MK, Campbell EG, Kesselheim AS. Changing interactions between physician trainees and the pharmaceutical industry: a national survey. J Gen Intern Med. 2013;28:1064-1067.

7. Austad KE, Avorn J, Kesselheim AS. Medical students' exposure to and attitudes about the pharmaceutical industry: a systematic review. PLoS Med. 2011;8:e1001037.

8. Hartman R, Blustein L, Morel D, Davis L. A pharmaceutical industry elective course on practice experience selection and fellowship pursuit by pharmacy students. Am J Pharm Educ. 2014;78:Article 126.

9. Mihm DJ. Using a marketing team approach to introduce students to pharmaceutical advertising and promotion: a focus on direct to consumer advertising appeals and executions. Curr Pharm Teach Learn. 2013;5:93-102.

10. Food and Drug Administration. Guidance for industry presenting risk information in prescription drug and medical device promotion. May 2009. https://www.fda.gov/downloads/drugs/ guidances/ucm155480.pdf. Accessed February 16, 2018.

11. Graves DA, Baker RP. The core curriculum for medical communications professionals practicing in the pharmaceutical industry. Ther Innov Reg Sci. 2000;34:995-1008

12. Academy of Managed Care Pharmacy (AMCP). The AMCP format for formulary submissions version 3.0. J Managed Care Pharm. 2010;16:Supplement 1.

13. USA Today/Kaiser Family Foundation/Harvard School of Public Health. The public on prescription drugs and pharmaceutical companies: summary and charts. https://www.kff.org/health-costs/ poll-finding/usa-todaykaiser-family-foundationharvard-school-ofpublic/. Accessed July 14, 2018.

14. Monaghan MS, Galt KA, Turner PD, et al. Student understanding of the relationship between the health professions and the pharmaceutical industry. Teach Learn Med. 2003;15:14-20. 15. Naik RK, Borrego ME, Gupchup GV, Dodd M, Sather MR. Pharmacy students' knowledge, attitudes, and evaluation of direct to consumer advertising. Am J Pharm Educ. 2007;71(5):Article 86. 


\section{American Journal of Pharmaceutical Education 2019; 83 (8) Article 7037.}

Appendix 1. Weekly Topics Covered in an Elective Course on Pharmaceutical Industry Practice

\begin{tabular}{ll}
\hline Sections & \multicolumn{1}{c}{ Topics } \\
\hline Medical Affairs & Legal and regulatory oversight of the pharmaceutical industry \\
& Introduction to medical affairs \\
& Principles of promotional review \\
Drug Development & Medical communications from a pharmaceutical industry perspective \\
& Drug development overview \\
& Translational medicine \\
& Clinical development \\
& Regulatory affairs \\
Customer Interface & Health economics and outcomes research \\
& Market access \\
& Field based medical affairs \\
& Scientific publication strategies \\
& Commercial marketing \\
& Leadership in business \\
\hline
\end{tabular}

Appendix 2. Learning Objectives for an Elective Course on Pharmaceutical Industry Practice

Explain the major federal laws and regulations that govern the pharmaceutical industry in the United States

Discuss the application of the following regulatory terms during the review of promotional advertising: on-label, off-label, claim, false and misleading, material facts, substantial evidence, fair balance, and materiality

Evaluate a direct to consumer prescription drug advertisement using principles of promotional review

Discuss the following regulatory violations related to promotional advertising: omission of risk information, minimization of risk, misleading claims, unsubstantiated claims, broadening of indication, and lack of adequate directions

Describe the position of medical affairs organizations within a pharmaceutical industry and discuss gaps in knowledge that create the need for these organizations

Demonstrate the ability to provide a written response to a drug information inquiry from an industry perspective using appropriate, critically evaluated primary medical literature

Discuss the following terms as it relates to good drug information practices: scientific balance, unsolicited requests for information, disclaimers

Discuss the pre-clinical, Phase 1, Phase 2, Phase 3, and Phase 4 stages of prescription drug development and the corresponding regulatory filing and agency interaction milestones in the United States

Describe the different types of clinical studies that can be used during the drug development process and discuss the contribution toward determining causation when evaluating clinical studies

Discuss the rationale supporting the importance of health economic and outcomes-based research for prescription drugs

Apply knowledge regarding types of health economic and outcomes research studies to recommend a strategy to define the value of a prescription drug product

Discuss the strategic value of field based medical affairs functions for the pharmaceutical industry

Describe the scientific publication landscape including authorship best practices 